\title{
Teaching Mathematics with Women in Mind
}

Jessica M. Deshler and Elizabeth A. Burroughs

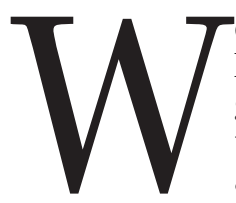

e both work at institutions that have been awarded NSF ADVANCE grants. ADVANCE is a program that aims to develop systematic approaches to supporting academic women in science, technology, engineering, and mathematics (STEM) disciplines. ADVANCE looks at universities and asks, "What support can universities provide to help women faculty members thrive in STEM?" We took that question to heart and asked ourselves, "What support can we provide in our undergraduate mathematics classrooms to help women students thrive in mathematics?"

We decided to take a hard look in the mirror. This meant examining our own approaches to teaching and confronting the limits of our own education and preparation. Trained as mathematicians, we found our preparation for understanding how gender affects undergraduate mathematics classroom environments lacking. We turned to resources from psychology, sociology, and women's and gender studies to better understand our own teaching. Our personal goal-it might not be yours-is to understand how gender bias influences our mathematics teaching and to explore concrete steps we can take to reduce the effects of that bias.

We've asked ourselves why our classrooms should look different from the classrooms in which we were undergraduate students. After all, we are both women who were successful undergraduate mathematics majors and went on to earn Ph.D.'s in mathematics. Call it survivor's guilt: we both know

Jessica M. Deshler is assistant professor of mathematics at West Virginia University. Her email address is desh1er@ math.wvu. edu.

Elizabeth A. Burroughs is associate professor of mathematics education at Montana State University. Her email address is burroughs@math.montana .edu.

DOI: http://dx.doi.org/10.1090/noti1042 that we were able to "fit in" in mathematics when many other women could not. We could say, "Other women should do what we did and learn to fit in." Instead, we are asking, "What should we do differently as mathematics instructors so that more women, who wouldn't otherwise be successful, will be and will persist in the study of our subject?"

We have to make a few stipulations. First, we believe teaching can be taught. Though trained as applied mathematicians, we both now do research in and teach mathematics education. Our work in mathematics education is guided by the belief that great teaching can be taught. This is contrary to what popular culture has us believe: often teachers are characterized as "born to teach." Sometimes great teachers believe it too. There is something to that-in the absence of preparation for teaching, there are those who will become better because they experiment, reflect, and revise their own teaching. They do this on their own and end up keeping the best of their experiments and learning from the ineffective ones. We don't mean to diminish the greatness of those who have figured out how to become great teachers on their own; we want to understand what they do in classrooms and teach others to do the same. As we explore changes to make in a classroom to be responsive to gender, we are thinking of explicit teaching choices.

Second, we believe there is inherent good in giving more people access to undergraduate mathematics. This is a value we stipulate. You might not share that value, but if that's the case, then you and we are aiming at different things. We've thought a lot about what kinds of good come from access to mathematics, and we believe that what might resonate most with our students is the access to fulfilling, higher-paying jobs that comes with advanced technological knowledge. Some may argue that this is not why we teach mathematics, but it 
is certainly why many of our students are taking mathematics classes. The mathematics classes we teach are populated with students who are taking the course because it is required by their major, because someone has decided what amount of mathematics they will need to know to be successful in their academic program (and ultimately in a career in their chosen field). Dudley [11] suggests that we "be a little less insistent that mathematics is essential for earning a living" and argues that texts such as Everybody Counts [26] overestimate the necessity of mathematics (and skills in algebra) for everyday life and work. He uses the telephone Yellow Pages headings of Janitor Service, Janitor's Equipment and Supplies, Jewelers, and others to support his point. We take the point of view that we are preparing students for career aspirations above and beyond those used in his example. The majority of students in calculus courses have chosen career paths where calculus is accepted as necessary or at the very least helpful. We therefore need to consider how to facilitate a greater understanding among students in our classes.

Finally, we are not psychologists, sociologists, or gender theorists. We are thinking about these issues on a very practical level-that of mathematics professors. But, to understand the practical, we've found we have to consider the theoretical. And we understand that our social scientist colleagues have something to tell mathematicians about how to teach mathematics. Indulge us-this article might take you out of your comfort zone and talk about some nonmathematical theoretical ideas that we think have an influence on choices we make when teaching mathematics.

\section{The Scenario}

Consider the following: you are teaching an upperlevel undergraduate mathematics course with about thirty students. Roughly one third of the students are women, and throughout the semester you notice that these women are some of your best students. In fact, none of the worst students are women. A careless analysis of this situation might lead you to believe that there is no gender disparity in undergraduate mathematics courses at your institution and, in fact, women seem to be advantaged, so you can focus on making your instruction as engaging as possible so all of your students will benefit. A more careful analysis would expose the selection bias inherent in your single classroom situation: your sample only includes those students who were successful enough in prior courses to be enrolled in an upper-level course. If there is no gender bias, then you should expect women to be proportionally represented throughout the grade distribution; instead, the lack of women in the mid-to-low performance range might indicate that women are being screened out of advanced undergraduate mathematics when men of similar performance levels are not [5]. Such a scenario is a call to all of us who teach mathematics to undergraduates to pay attention to issues of equity.

\section{What Are We Teaching Our Students?}

Students in undergraduate mathematics courses are generally exposed to a breadth and depth of mathematical content. In recent years a focus on conceptual understanding has led to a curriculum reform movement in mathematics across all school levels, a movement that is focused on conceptual rather than procedural understanding of mathematics. Conceptual understanding is one of five components of mathematical proficiency for children identified by the National Research Council [25], and researchers have called for a priority on conceptual learning in higher education in general [20]. While true for mathematics and higher education independently, this has been especially true for their intersection in the reform of undergraduate mathematics. Specifically, calculus has been at the center of a reform movement since the 1980s and is seen by many in higher education as a gateway to STEM majors, since success in this course is a requirement for entry into many STEM programs.

What are absent from this mathematical experience (and reform movements), however, are explicit discussions with students about the opportunities they'll have when they've taken more mathematics content courses. Undergraduate students do not have a chance to examine how mathematical knowledge translates into social and economic power by increased access to careers that are influential or high paying. Psychologists call this the "utility value" of mathematics. This utility value is often overlooked [18] despite the fact that researchers have called for students to obtain a cultural awareness of the significance of mathematics in the larger worlds of science and society [2]. Instructors of undergraduate mathematics can facilitate this awareness by incorporating this utility perspective into courses. Indeed, engineering has had great success with such a curriculum overhaul; incorporating examples and demonstrations that contextualize and draw the social and community connections for students has been shown to enhance performance and interest of both male and female engineering students [6].

We recently tried out a classroom activity as a way to promote an awareness of the utility value of mathematics. An instructor of a Calculus I course at one of our institutions introduced the utility value of mathematics to show students how the calculus concepts they were learning can be used to address societal problems. The instructor prepared a short presentation (four slides) describing the uses of mathematics beyond what students may normally think about when in a mathematics class. On this day in class, students 
saw how mathematics is applied in political science (in the effect of weighted voting, coalitions and bloc voting, particularly timely given the U.S. presidential election at that time), national security (how disease spreads, bioterrorism, screening airline passengers, disaster response), and issues of social justice (in economic models for povertystricken nations). Each example presented came from a scholarly article to show students how researchers in these fields use mathematics, specifically the calculus they were studying in class, to address these problems. In addition to telling the students how calculus can be used in fields that might appeal to them, students were asked to take part in increasing their awareness through one homework assignment. They had to find, read, and summarize a scholarly article demonstrating calculus applied to a problem in their major academic fields over the course of one week. Through statements students made in their written summaries (e.g., "I never knew calculus could be applied to biology"), we were able to see a clear increase in utility-value awareness in this class from even just one assignment.

\section{What Else Can We Do?}

Beyond developing curriculum related to utility value, we've also considered teaching practices which help our students set appropriate classroom behaviors. We aren't talking about listing classroom rules on the syllabus; we wanted to have students develop classroom habits that we would consider mathematically productive. We looked into feminist teaching and encountered the ideas of authority, agency, and voice. We've been thinking about what those ideas mean in a context that is mathematical. This article describes our interpretation of how undergraduate classrooms can reflect mathematical authority, mathematical agency, and mathematical voice as ways to encourage all students, with the specific aim of engaging more female students to persist in mathematical study.

We're concerned with understanding how the issues of authority, agency, and voice are present in a classroom where the academic topic is mathematics. We want to know: what does it mean to have mathematical authority, mathematical agency, or mathematical voice? We consider where our students find authority in the mathematics classroom. Is the source internal or external? Is it the instructor? Or is it the mathematics? Do our students act as agents for themselves, taking action where appropriate? Do they exercise a voice in the classroom, speaking from an authentic, individual perspective rather than being limited to repeating the ideas of others? One thing to keep in mind is that social scientists confer academic meaning on the terms authority, agency, and voice in a way that is related to the common English connotation of the words but is not identical to it (think of the precision that mathematicians invoke when using the words similar, random, or equal). In what follows, we try to offer our interpretation of the academic use of those words.

\section{Mathematical Authority}

We suggest that it is most natural for mathematicians to understand the teaching construct of authority because the discipline of mathematics rests on a structure that is internally derived and verified. Educational and social theorists define different types of authority, including traditional authority (a right to command and a duty to obey) [35] and professional authority (based on expertise needed to achieve aims) [3]. Though classrooms might rely on these (and other) authority structures, mathematicians themselves recognize in doing mathematics that it is mathematical reasoning and the verification of that reasoning that characterizes the discipline. Then what characterizes classrooms where the authority structure reflects the premise of mathematical authority?

Despite efforts in collaborative learning, many students still view their instructors or their textbooks as the final authority on mathematical correctness [29]. In fact, it is easy for mathematics instructors to take this point of view as well, since they are the experts in the subject matter. Instructors need to instill in students an understanding of the authority inherent in the discipline. This, however, is easier said than done, and for many of us the attempt is familiar territory. We try to have discussions encouraging students to work out problems on their own or with classmates before seeking instructor intervention, yet still hear "I'll just wait for the professor to do it" as we walk away.

There is a need for instructors to develop methods of promoting self-reliance in students or risk perpetuating a culture in which students are unable or unwilling to solve mathematical problems (or conduct themselves in mathematical situations) without access to expert knowledge. If our students are relying on us to provide the authority in the classroom (instead of relying on the mathematics), then it is natural for us to conclude that either the students think themselves unable to do the mathematics or the students are able but unwilling. Students in the first group-those who don't believe they are capable of doing the mathematics-will feel they need to mimic the instructor. Those in the second group-unwilling to try-may believe the instructor is the expert and should be mimicked.

The first group of students does not believe they can do mathematics regardless of the effort they put in. They consider themselves outside a marked group [7] of people who have mathematical ability. Considering themselves outside this group, they 
are merely able to reproduce the mathematics of others but not able to engage with the mathematics in a meaningful way. They see themselves only as copiers of others' mathematics [21] and are therefore unable to see where mathematics fits into the world around them. They will likely be unable to function in a mathematical situation outside the classroom without expert knowledge as a resource.

The second group, students who think simply mimicking their instructor's mathematical processes is acceptable, does not see the need to understand mathematics, because they have an expert mathematician in the classroom. Their inability to see mathematics beyond the classroom places them in the same situation as the students in the first group-unable to function in a mathematical situation without expert knowledge as a resource. We suggest that mathematicians teaching undergraduate courses consider whether their classroom approach encourages students to find mathematical authority from an external expert or from within mathematics itself. One way to foster a reliance on the internal authority of mathematics and promote agency and voice among students is through focusing on appropriate use of group work. Collaborative groups, as a pedagogical tool, allow students to express themselves mathematically, and women in particular have shown positive reactions to collaborative learning [32]. By participating in groups, students can practice developing their own voice and agency; they can learn to put their own mathematical ideas forward to peers and validate their reasoning.

An instructor at one of our institutions recently attempted to use video self-modeling (VSM) to reinforce effective group work practices among calculus students to promote the constructs described above. VSM is the activity of watching and learning from one's own positive behavior [4]. Group work is an integral part of the course, though getting students to "buy in" to group work and step away from the traditional lecture format of a mathematics class is sometimes difficult. (It should be noted that several of the group work activities used in this project are research-based supplemental curriculum materials which were implemented several years prior and the instructor was experienced in facilitating the activity.) VSM has been used in educational and psychological research to reinforce positive behaviors since the 1970s.

Prior to attempting the VSM activity, the instructor engaged the students first in small group discussions, then a whole class discussion around a series of questions designed to help them identify effective group work behaviors and discuss their attitudes toward collaborative work in a mathematics class.

During a later class, while working on a groupwork activity (though not one of the activities common to all classes), three groups of students were videotaped. The instructor's plan was to sift through the three videos to find a short clip where students were modeling the behaviors they previously described as effective (things like sharing responsibility for the group's work, discussing mathematics in a way that builds on other students' contributions). However, in the 42 minutes of videotaping, the instructor was unable to find even a 30-second video segment in which students were, in fact, displaying the desired behaviors.

Instead, the instructor created the desired video clip with graduate teaching assistants portraying students while working through the activities. The teaching assistants were familiar enough with the mathematical content of the tasks that they were able to focus on modeling the desired behaviors. This is the video the instructor eventually used in her video-modeling intervention. After watching the video, the undergraduate students had a productive discussion about how to engage in groups. Informal reports from the instructor are that this activity did help the students in their collaborative work for the remainder of the semester.

\section{Mathematical Agency}

The psychological construct of agency is, we propose, less obvious to mathematicians than that of authority. In considering agency, theorists consider an individual's ability to take action for him- or herself. We refer to the common definition of agency: the capacity to act or exert power. Researchers have called for mathematics educators to provide students with "tools to analyze and act upon issues important in their lives, in their communities, and to society in general" [14, p. xxi]. We have thought about how to interpret agency in mathematics classrooms and have found the ideas of mindset and motivation are those we can best understand and enact.

Mindset for Learning. Psychologists refer to an individual's mindset as the underlying beliefs about intelligence or ability that the individual holds. Mindsets are generally classified into two categories: a fixed mindset or a growth mindset. The fixed mindset, sometimes called an entity view, is characterized by the belief that intelligence or ability is fixed and a person either has the intelligence or ability or does not. The growth mindset, sometimes called an incremental view, is characterized by the belief that a person's intelligence or ability is malleable and changes with effort [12].

Psychologist Carol Dweck [12] has identified three features of learners with a growth mindset. Those with a growth mindset are focused not on high scores or grades but on learning; they believe that the amount of effort is what determines achievement; and they tend to use positive strategies when they face difficulty, such as changing problem-solving approaches. 
There is evidence that shows that providing learners with a growth mindset can positively impact learning outcomes in mathematics and science. In a study of college chemistry courses, Grant and Dweck [17] studied how growth or fixed mindsets affected grades in this difficult course. They found, among other things, that growth mindset students were better able to recover from a setback (a low exam score) than fixed mindset students. They also found that mindset had a gender dimension: of those with a fixed mindset, men outperformed women. But with a growth mindset, women and men were statistically level.

Specific to mathematics, Good, Rattan, and Dweck [15] studied the mindsets of females in college calculus and found that women with a growth mindset were less susceptible to negative stereotypes and indicated a feeling that they "belong" in math, more so than women with a fixed mindset. Other studies by these authors [16] have shown that describing "math geniuses" as people who love and work at mathematics rather than as born geniuses provides students with a growth mindset about mathematics. In another study, Dar-Nimrod and Heine [8] found that females who are exposed to the idea that differences in mathematics are due to experience rather than genetics perform better on a mathematics performance task.

This research indicates that it is important to address students' mindsets in the classroom if the classroom goal is to develop critical thinking skills with respect to mathematics in more students. Instructors can provide students with the tools to understand and adopt a growth mindset. Perhaps this can be achieved by extending some of the strategies suggested for teaching children to have a growth mindset to higher education and by showcasing mathematicians (including women mathematicians) as hard workers. Alternatively, mathematics instructors providing students with examples (in the mathematics classroom) of how mindset can affect performance in other fields can provide a model of the relationship between the two (performance and mindset) and further a belief in growth mindset.

During a recent calculus class, a graduate instructor at one of our institutions attempted this by providing real-world examples during a classroom discussion to illustrate to the students how much of an impact our own thoughts can have on our performance. They listened to excerpts from stories in sports where positive thinking led to record breaking, among other things. Both strategies are relatively simple to implement and are well received by students in general.

\section{Motivation in Mathematics}

Within the academic discipline of psychology there is a subfield that is concerned primarily with motivation. It is not the purpose of this section to elucidate all of the subtleties included in a rich knowledge of that field. Rather, this brief discussion is meant to provide an overview of motivation that will enable the mathematician or mathematics educator to be aware of the most widely agreedupon impacts of the psychology of motivation in the mathematics classroom. To some psychologists, agency is considered a subconcept of the concept of motivation. We freely admit that we understand these concepts only through a layperson's view. With this as our lens, we choose to characterize attention to motivation as a way to promote agency within students in a classroom.

Key concepts in educational psychology that relate to motivation (in its academic usage) are goals, interest, and motivation (common English usage). According to Murphy and Alexander [22], who analyzed psychology literature for definitions in motivation, a goal is generally defined as that which students wish to achieve; an interest is the process "by which the underlying needs or desires of learners are energized;" and motivation is a process involved in the direction, intensity, and persistence of behavior [22, p. 28].

Students who are "goal-oriented" may have a specific goal as their aim. This may be a performance goal (earning a high grade or avoiding a failing grade), a mastery goal (to learn the material), a social goal (to fit in with peers, the teacher, or some other social community), or a work-avoidance goal (doing as little work as possible). There has been recent interest among research psychologists in refining this structure used to categorize goals [13], but the four categories suggested here can aid the mathematician's understanding of students' goals. It is often easiest in classroom settings to appreciate the student who has a mastery goal, and it can be frustrating to deal with students who have a work-avoidance goal. Students with performance goals might consider themselves "good" students; instructors who understand the difference between performance goal-oriented and mastery goal-oriented students may find opportunities to engage the performance goal-oriented students in activities that display the value of concept mastery. Classrooms that acknowledge students' social goals may find strategies to structure the classroom environment around a shared mathematical community.

Interest can be categorized as individual or situational interest. Students may have individual interest, which means that they have developed an interest in specific classroom material that comes from their prior interactions with or knowledge about the subject, or students may have situational interest, an interest that is more malleable and context dependent. It may be beneficial for teachers to focus instruction on situational interest in an attempt to embed ideas that can become individual interest [28]. 
Students may be motivated intrinsically, which is a feature that comes from the task in and of itself, or extrinsically, meaning they are performing the task to get some benefit or meet some other goal that is peripheral to the activity itself. Instructors who choose mathematics tasks that are relevant to students' interests may have more success tapping into students' intrinsic motivation [9].

Both of the strategies that we've discussed earlier, focusing on meaningful problems in the curriculum and explaining the utility value of mathematics to students, are ways we've tried to address motivation in classrooms.

\section{Mathematical Voice}

The idea of voice is the hardest for us to get a handle on. Sometimes it is hard for us to understand the distinction between some ideas that social scientists present related to voice and those related to agency or authority. Rather than focusing our energy on understanding those distinctions that seem far outside our expertise, we have tried to understand what new ideas are encompassed within voice that we haven't yet explored. We propose that there are two aspects of mathematical voice that should be understood in relation to undergraduate mathematics: voice in the classroom and voice in society.

In one respect, a classroom that allows students mathematical voice is one in which students are literally speaking. But the idea of voice goes deeper than this. A classroom that attends to mathematical voice provides all students the opportunity and expectation to be engaged in the intellectual content of the classroom. This involves instructors using strategies that ensure all students are called on or share ideas vocally in an equitable way but also uses written assignments as ways to engage students' voices. Many of the issues of this aspect of voice overlap issues of mathematical authority and agency that have been previously discussed. A second aspect of mathematical voice is an understanding of what it means to have a mathematical voice in society at large. To understand that perspective, we found ourselves examining the sociological construct of privilege.

We think of privilege as a special advantage granted to a person or group of people not always deserved or earned. Privileged people in the United States tend to be male, white, middle or upper class, heterosexual, and physically and mentally able [24]. People in privileged groups are generally unaware of the advantages they obtain simply by belonging to this class based on their race, ethnicity, gender, or socio-economic status.

People of color or lower economic status are usually not afforded the same advantages as those in a privileged group. Researchers have shown that mathematics education has afforded privilege to some students while limiting opportunities for others, and trends in mathematics achievement continue to persist along racial, ethnic, gender, and socio-economic status among students [30], [31]. In addition to privilege affecting the type, quality, or level of mathematics education received by students, the level of mathematics education received by students will affect their future privilege in the access it gives them to career choices. This cyclic relationship between privilege and mathematics education in our society is one which we try to recognize in class.

It is difficult to balance the advantages afforded to those with privilege and those without, even in the relatively small and controlled environments of the classroom. As such, we don't have good suggestions or even examples of what we've tried. As a first step, we suggest that mathematics instructors seek to notice the ways that privilege emerges in the classroom environment: who talks more in class or who has stronger prerequisite skills, for example. Perhaps with greater awareness we can find ways to address this issue more concretely.

\section{Discussion}

Our personal purpose in understanding the constructs of authority, agency, and voice in mathematics is to attempt to address the gap between the numbers of women and men who pursue mathematics careers, and we began by inspecting our own classrooms. The transition between high school and college is a critical time when many young women turn away from STEM career paths. Only half as many female first-year students plan to pursue STEM majors as their male counterparts [27], and of those who do major in STEM, women leave these majors at the same rate as men [33].

Current literature investigating why there are so few women in STEM reveals the following three themes: (1) the existence of perceived gender differences (the continued notion that men are mathematically innately superior and therefore better suited to careers in STEM), (2) the lack of interest in STEM by women, and (3) the influence of the STEM workplace environment [1]. Recently, researchers have also identified a lack of focus on the communal and social values that a STEM career affords as another possible deterrent to women's participation [10]. We suspect the lack of knowledge of the social value of STEM careers greatly contributes to the lack of interest in STEM by women.

Given these three influences, namely, the persistent lack of women in STEM majors and careers, the trend toward mathematics instruction that is both conceptual and attentive to societal issues, and the recognition of the value of including women's perspectives in creating a sense of belonging, we suspect that an understanding of the issues of authority, agency, and voice is a first step and a 
critical foundation towards creating classrooms that foster a sense of belonging among women.

Mathematical knowledge is an instrument of economic potential for individuals in society. The U.S. Department of Labor projected that, in 2012, nine out of ten of the fastest growing occupations will require preparation in mathematics or science [34]. Additionally, careers that require this type of preparation equip degree recipients with higher earning power. For example, in 2012 the average starting salary for a bachelor's degree recipient entering non-STEM fields was much lower than recipients of degrees in STEM fields [23]. In particular, women in science and engineering tended to earn more than women in other sectors of the workforce. A recently published analysis of gender differences in mathematics performance at the K-12 level found evidence to support the hypothesis that socio-cultural factors in environment result in the observable differences in boys' and girls' performance in mathematics [19] and concluded that "eliminating gender discrimination in pay and employment opportunities could be part of a win-win formula for producing an adequate supply of future workers with high-level competence in mathematics" (p. 19).

These societal factors illustrate the importance of engaging women in mathematics in their undergraduate careers. We propose that teaching that attends to mathematical authority, mathematical agency, and mathematical voice will help all students, including women, as a way to address the STEM pipeline problem at the early undergraduate level.

\section{Acknowledgment}

Partial support for this work was provided by the National Science Foundation's ADVANCE IT Program under award HRD-1007978. Any opinions, findings, and conclusions or recommendations expressed in this material are those of the authors and do not necessarily reflect the views of the National Science Foundation.

\section{References}

[1] American Association of University Women (2010), Why So Few? Women in Science, Technology, Engineering, and Mathematics, Washington, D.C.

[2] H. BASS (2003), The Carnegie initiative on the doctorate: The case of mathematics, Notices of the American Mathematical Society 50(7), 767-776.

[3] P. BLAU (1974), On the Nature of Organizations, New York: John Wiley.

[4] T. Buggey and L. Ogle (2012), Video self-modeling, Psychology in the Schools 49(1), 52-70.

[5] E. A. Burroughs and J. M. Deshler (2013), Gender Bias? The College Mathematics Journal 44(3).

[6] P. CAMPBELL, E. PATTERSON, I. BuSCH-VishniAC, and T. Kibler (2008), Integrating applications in the teaching of fundamental concepts (AC 2008-499), A Presentation to the American Society for Engineering Education (ASEE), Pittsburgh, PA, June 25, 2008.
[7] S. K. DAMARIN (2000), The mathematically able as a marked category, Gender and Education 12(1), 69-85.

[8] I. DAR-NimRoD and S. J. HEINE (2007), Exposure to scientific theories affects women's math performance, Science 314, 435.

[9] E. L. Deci, R. M. Ryan, and R. Dienstbier (1991), Perspectives on motivation, Lincoln: University of Nebraska Press.

[10] A. B. DiekMAN, E. R. Brown, A. M. Johnston, and E. K. CLARK (2010), Seeking congruity between goals and roles: A new look at why women opt out of science, technology, engineering, and mathematics careers, Psychological Science 21, 1051-1057.

[11] U. DuDLEY (2010), What is mathematics used for? Notices of the American Mathematical Society, 57(5), 608-613.

[12] C. DwECK (2008), Mindsets and Math/Science Achievement, New York: Institute for Advanced Study, Commission on Mathematics and Science Education, Carnegie Corporation of New York.

[13] A. J. Elliot and H. A. MCGregor (2001), A 2×2 achievement goal framework, Journal of Personality and Social Psychology 80(3), 501-519.

[14] P. ERneST, B. GREER, and B. SRIRAMAN (2009), Agency in mathematics education, Critical Issues in Mathematics Education, pp. ix-xvi, P. Ernest, B. Greer and B. Sriraman (eds.), Charlotte, NC: Information Age Publishing.

[15] C. GOOD, A. RATTAN, and C. S. DwECK (2012), Why do women opt out? Sense of belonging and women's representation in mathematics, Journal of Personality and Social Psychology 102(4), 700-717.

[16] C. Good, C. S. Dweck, and A. RATTAN (2005), An incremental theory decreases vulnerability to stereotypes about math ability in college females, unpublished data, Columbia University.

[17] H. GRANT and C. S. DWECK (2003), Clarifying achievement goals and their impact, Journal of Personality and Social Psychology 85, 541-553.

[18] C. S. Hulleman, O. Godes, B. L. Hendricks, and J. M. HARACKIEWICZ (2010), Enhancing interest and performance with a utility value intervention, Journal of Educational Psychology 102(4), 880-895.

[19] J. KANE and J. MERTZ (2012), Debunking myths about gender and mathematics performance, Notices of the American Mathematical Society 59(1), 10-21.

[20] E. MACLELLAN (2005), Conceptual learning: The priority for higher education, British Journal of Studies 53(2), 129-147.

[21] K. R. MuIs (2004), Personal epistemology and mathematics: A critical review and synthesis of research, Review of Educational Research 74(3), 317-377.

[22] P. K. MurPhy and P. A. AleXANDER (2000), A motivated exploration of motivation terminology, Contemporary Educational Psychology 25, 3-53.

[23] National Association of Colleges and Employers (2012), Salary survey: April executive summary, Bethlehem, PA, retrieved August 1, 2012, from www. naceweb.org

[24] National Council of Teachers of Mathematics (2001), Changing the Faces of Mathematics: Perspectives on Gender, Reston, VA.

[25] National Research Council (2001), Adding It Up: Helping Children Learn Mathematics, Washington, D.C.: The National Academies Press.

[26] National Research Council (1989), Everybody Counts: A Report to the Nation on the Future of Mathematics 
Education, Washington, D.C.: The National Academies Press.

[27] National Science Foundation, Division of Science Resources Statistics (2009), Women, minorities, and persons with disabilities in science and engineering: 2009 (NSF 09-305), Arlington, VA: Author, retrieved June 23, 2011, from www.nsf.gov/statistics/ wmpd.

[28] K. A. RENNINGER, C. SANSONE, and J. L. SMITH (2004), Love of learning, Character Strengths and Virtues: A Handbook and Classification, pp. 161-179, C. Peterson and M. E. P. Seligman (eds.), New York: Oxford University Press.

[29] A. H. Schoenfeld (1985), Mathematical Problem Solving, New York: Academic Press.

[30] W. G. SECADA (1992), Race, ethnicity, social class, language, and achievement in mathematics, Handbook of Research on Mathematics Teaching and Learning, pp. 623-660, D. A. Grouws (ed.), New York: Macmillan.

[31] W. F. Tate (1997), Race-ethnicity, SES, gender and language proficiency trends in mathematics achievement: An update, Journal for Research in Mathematics Education 28(6), 652-679.

[32] K. L. TONSO, R. L. Miller and B. M. OlDS (1994), Student Learning and Gender Issues in a Nontraditional Engineering Class: Implications for Engineering Education, Proceedings of the American Society for Engineering Education Annual Conference.

[33] U.S. Department of Education, National Center for Education Statistics (2000), Entry and Persistence of Women and Minorities in College Science and Engineering Education (NCES 2000-601), by G. Huang, N. Taddese and E. Walter, Washington, D.C.

[34] U.S. Department of Labor, Bureau of Labor Statistics, (2009), Women in the Labor Force: A Databook (Report 1018), Washington, D.C.

[35] M. WEBER (1947; original work published in 1925), The Theory of Social and Economic Organization (A. M. Henderson and T. Parsons, transl.), New York: Free Press.

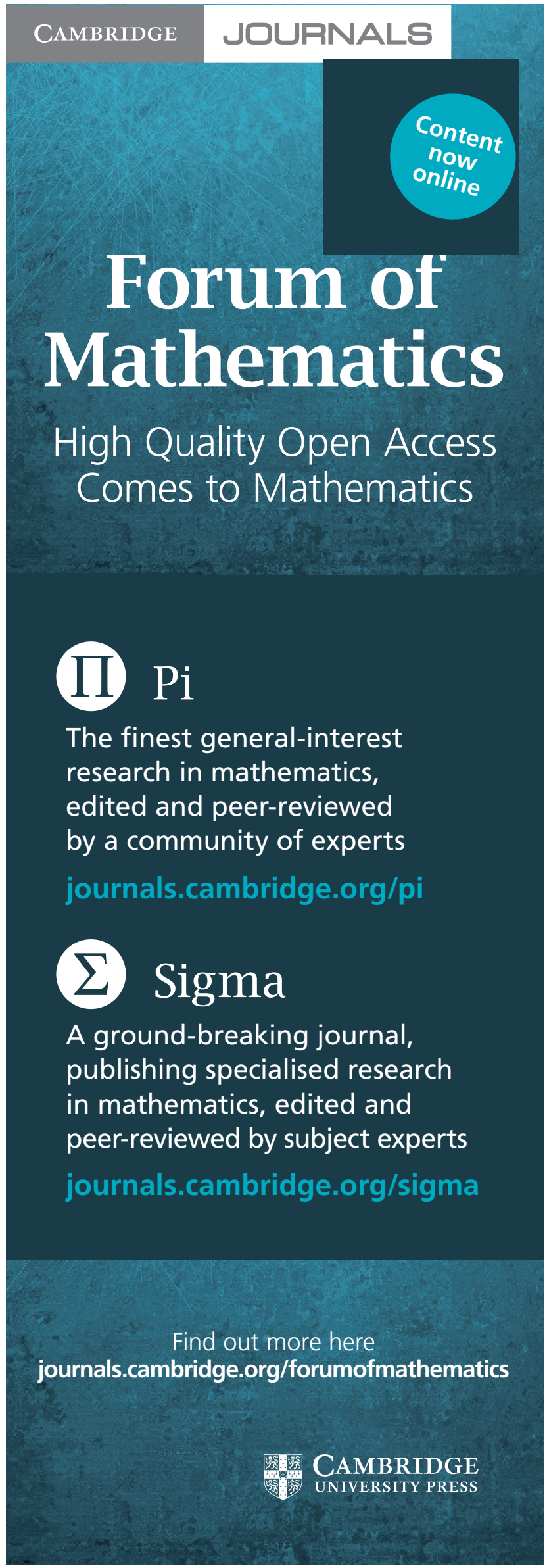

